Article

\title{
Rethinking Public Agenda in a Time of High-Choice Media Environment
}

\author{
Sara Bentivegna ${ }^{1}$ and Giovanni Boccia Artieri ${ }^{2, *}$ \\ ${ }^{1}$ Department of Social Sciences and Economics, Sapienza University of Rome, 00100 Rome, Italy; \\ E-Mail: sara.bentivegna@uniroma1.it \\ 2 Department of Communication Sciences, Humanities and International Studies, University of Urbino Carlo Bo, \\ 61029 Urbino, Italy; E-Mail: giovanni.bocciaartieri@uniurb.it \\ * Corresponding author
}

Submitted: 15 April 2020 | Accepted: 4 June 2020 | Published: 8 October 2020

\begin{abstract}
Contemporary political communication is conditioned by an information environment characterised, on the one hand, by increased choice, and on the other by the fragmentation and multiplication of the ways of consuming information. This article introduces the notion of the 'interrelated public agenda' as a frame to study this context, taking into account elements of convergence and divergence from a single viewpoint, adopting a complex analysis model which proceeds along axes which make it possible to detect a continuum in which opposing forces are in a constant, problematic equilibrium. In this sense, we identified three dimensions which are helpful in describing public agenda interrelations. First, horizontality vs verticality, which contains the dynamics of power, and is generated in a context of political disintermediation, through the altered nature of the media system - in the complex relation between legacy media and web 2.0, and between social, institutional actors, and others. Second, personal vs aggregative, which stresses the need to take account of convergences and divergences between personal orientation towards certain issues and the aggregative pressure in different media spaces in which people feel at home: from information consumption via media diets of varying complexity to active participation in the production of content or in public discourse, offline and online. And finally, dynamic vs static, which points to the need to orient analysis towards the relation between media spaces rather than focusing on specific spaces, thus helping, importantly, to make up for the current dearth of research in comparison with studies of single platforms.
\end{abstract}

\section{Keywords}

legacy media; media environment; political communication; public agenda; public sphere; social media

\section{Issue}

This article is part of the issue "The Ongoing Transformation of the Digital Public Sphere" edited by Emiliana De Blasio (LUISS University, Italy), Marianne Kneuer (Hildesheim University, Germany), Wolf J. Schünemann (Hildesheim University, Germany) and Michele Sorice (LUISS University, Italy).

(C) 2020 by the authors; licensee Cogitatio (Lisbon, Portugal). This article is licensed under a Creative Commons Attribution 4.0 International License (CC BY).

\section{Introduction}

That a well-functioning democracy needs citizens who are at least minimally well-informed about matters of public importance is a widely held assumption (Dahl, 1998); how that information is be obtained, though, is a question inevitably affected by the media system in which we are placed and by the power relations existing between the various actors. It is clear that in the name of pluralism and difference, the aim of channeling citizens into a single sphere, in particular, significantly changes how they learn about political and current affair news (Shehata \& Strömbäck, 2018). It is equally clear that the acquisition of information depends, first and foremost, on the interest shown by the citizens themselves, who are less and less synonymous with the "informed citizen" and more and more with the "monitorial citizen" (Schudson, 1999). Whichever citizen is chosen for reference, the effective availability of information proves indispensable to the orderly working of democratic institutions. However, in contemporary societies, the most widely shared concern, except in some rare cases, is not 
the shortage of information, but the very opposite-the abundance of information. Hence, if in the past the issue at stake was the real availability and accessibility of information for all citizens, as well as the opportunity to allow space for different and contrasting interests, the focus today is on the consequences of a communicative and informative surfeit which certainly makes for diversification, but also for fragmentation.

The clearest evidence of this interest is to be found in the emphasis placed on the spread and centrality of echo chambers, described as the perverse effect of the multiplication of voices on the net and of the hemophiliac tendencies of the individual. The truth of the matter is that the phenomenon has been considerably overestimated so much so as to overshadow other questions, like the survival/transformation of the public agenda in a high-choice media environment. The adoption of a crossmedia research approach after years of exclusive concentration on social media has again raised the question of a convergent public agenda. This article aims to examine afresh the concept of public agenda and to argue that it is still possible to talk about it, albeit in different terms than in the past. More precisely, we think that it is possible to talk about an 'interrelated public agenda,' which can be defined and traced thanks to the use of specific dimensions. Structured in five parts, the article begins by analysing the fragmentation of the media environment in which we are placed today; Section 3 deals with the central role of the public agenda in the study of contemporary political communication; Section 4 with the variables of the 'interrelated public agenda,' i.e., an agenda that is possible to trace in the contemporary context; Section 5 with the dimensions of the interrelated public agenda' seen in relation to the challenges to our conceptualisation of the public sphere in a multiplicity of public spheres; and Section 6 ends the article with a discussion of our proposal and some general conclusions about the survival/transformation of the public agenda and public sphere.

\section{The Fragmentation of Media Environment}

The tradition of studies of agenda-setting has showed how the salience of issues on the media's agenda influences the salience of the same issues on the public agenda: In this sense we can say that the media's agenda set the public's agenda. These studies point out how, at a first level, the media influence the perception of the hierarchy of topics; at a second level, how they structure the public's knowledge of these topics (their salience); and, at a third level, that research on agenda-setting effects point out how media can influence an integrated picture of these attributes (McCombs \& Guo, 2014). In this sense, news media play a central role in building a public agenda and in citizen participation in the public sphere.

Although over the years the dominant attention of agenda-setting studies has focused on a particular aspect of its theory-the transfer of issue salience from the news media to the public agenda-in the last decade other research "has expanded to include many other channels of communication-political advertising, conversations, and social media" (McCombs, Shaw, \& Weaver, 2014), observing the new media ecosystem, the impact of the networked media agenda on the networked public agenda, and how this affects the public sphere.

The abundance of communication, typical of the current media ecosystem, stems from the transformations introduced by the Internet and social media, as regards the production, distribution, and consumption of information, and the interconnections between mass media logic and networked media logic (Klinger \& Svensson, 2015). Various scholars have indicated just how complex and problematic the impact of digital media on a shared public space is. Dahlgren (2005), for example, while welcoming the opportunity to extend and pluralize the public sphere, draws attention to the risk of dispersion and of a cacophony of voices, leading to the inevitable fragmentation of the public agenda and audience. In an essay which has become a classic of media studies, Bennett and lyengar (2008) have underlined how audience fragmentation, combined with channel proliferation, reduced the opportunities for casual contact with content that is not deliberately selected, and increased the opportunities for consuming content in line with pre-existing attitudes. In short, they recognized the typical ingredients of the fragmentation/polarization phenomenon which, some years later, would be the focus of studies on the fourth age of political communication (Blumler, 2016). This age can be described in terms of the coexistence of: a) a high choice media environment; and b) the fragmentation and multiplication of the means of consuming information. In developing simultaneously, these traits create an effect of centrifugal diversification, producing "a vibrant communicative sphere" (Blumler, 2016, p. 4) more "sensitive" to voices gaining expression, thanks, not least, to the success of the social media. Despite the fragmentation which inevitably ensues, it is still possible, according to Blumler (2018, p. 89), to talk about a "networked public sphere, albeit a rather chaotic one." Thus, while the contemporary public sphere can be considered chaotic, it certainly cannot be assumed that it no longer exists.

The challenge of studying what constitutes the chaos, divergence, dissonance, and disruption of the public sphere has been taken up and reissued by other scholars interested in tracing the transformations of political communication in a high-choice media environment. Bennett and Pfetsch (2018, p. 249) explicitly urge us to focus attention on the fact that "there are many media agendas running through mainstream and niche media and across digital platforms and blogs, which seldom converge in the authoritative power to set the 'public agenda."' This is in line with the recommendation to "analyse online and offline dissonant public spheres and ask how they relate to each other and which functions they fulfill in political communication" (Pfetsch, 2018, p. 63). 
Hence, the dissonant elements singled out by many scholars in relation to the public sphere do not necessarily lead to the disappearance of a public agenda or to it simply being replaced by an idea of multiplied agendas, fragmented and unconnected from one another. Rather, the transformations of the public sphere by dissonant and more "sensitive" means than a multiplicity of noninstitutionalized actors points to the need to contextualize the idea of public agenda in an "information environment shaped by the behavior of political actors as well as media actors and ordinary citizens, with reciprocal influences on all sets of actors" (van Aelst et al., 2017, p. 6).

It is necessary to bear in mind the characteristics of this media environment and the reciprocal influences among the various actors involved in the production of the public agenda; it is equally important, however, to recognise that "there are reasons to be concerned about increasing fragmentation and polarization, but that this concern needs to be tempered by empirical findings which show that neither the supply nor the demand for biased information is as widespread as is sometimes claimed" (van Aelst et al., 2017, p. 14). The appeal for caution voiced by van Aelst et al. (2017) as to the true extent of the fragmentation and polarization phenomena marks a turning point after a lengthy period in which a sometimes exaggerated emphasis was placed on the spread of forms of communicative self-segregation habitually practised by individuals when consuming political information.

In other words, the real or potential dissonance of the public agenda caused by the abundance of communication-understood as the product of numerous channels, numerous devices, numerous messages, and numerous actors - has often been operationalized as an inevitable proliferation of multiple agendas, unrelated to one another and to the more general context in which they are placed. Thus, instead of considering the public agenda as 'interrelated,' it has been ascribed and confined to the specific communicative environments in which it is created, in a state of isolation and separateness.

\section{The Public Agenda between Legacy and Social Media}

As many scholars have pointed out, despite undoubted signs of dissonance and disconnection, the public agenda is still central to the study of contemporary political communication. From the earliest studies carried out at a time when blogs had assumed a central role in the public political debate, it was immediately clear that the contents produced by bloggers and those produced by the legacy media were thematically convergent: "The media agenda is fairly stable across news outlets despite growing diversification of information channels" (Kook Lee, 2007 , p. 754). This interrelation is further confirmed by Maier's (2010) comparative study of websites news, traditional newspapers, television, and radio.

Communication abundance, with attendant centrifugal diversification, does not appear to be reflected to any significant extent in the information provided by the individual media outlets. Even in the presence of environmental pressures designed to guarantee recognizability within what has been called the marketplace of attention (Webster, 2014), the agenda continues, to a large extent, to be shared, confirming that "the norms that govern the media overall are often more important than what distinguishes one form of media from another" (Strömbäck \& Dimitrova, 2011, p. 33). The existence of shared norms and procedures in the field of journalism tends to promote the convergence of agendas, especially for public events and breaking news (Djerf-Pierre \& Shehata, 2017).

The introduction of references to the platform characteristics which determine the outlet's publication cycle does not jeopardize the existence of a common agenda, but confirms and reinforces structuring in terms of "vertical media" (TV news and mainstream newspapers) and "horizontal media" (cable news and websites; Shaw \& Weaver, 2014). The same is not true of the introduction of references to the enlargement of the sphere of action of those who can contribute to building the agenda. In the past, one could talk of the interaction of politicians and journalists as a dance, but today it is more complex and produces wholly new dynamics. This is especially true of the social media, a stage on which political actors, activists, backers, and ordinary citizens can champion causes and take stances with a view to gaining greater visibility for certain issues and mustering support. To sense the importance of this, one need only cite the transformation of the information cycles in the interaction between legacy media and social media, detailed so effectively by Chadwick (2013).

It is no accident that this is the research area most favoured by scholars who are as interested in analysing the public agenda as the intermedia agenda, understood as transference of issues salience across media (McCombs et al., 2014). The intermedia agenda approach examines the ability to dictate the issues for the media agenda in its entirety and/or for the individual media outlets (Conway, Kenski, \& Wang, 2015). The centrality of the social media, and Twitter in particular, has kindled a keen interest in its agenda-building role, spanning an interlinked continuum which ranges from the top-down dominance of the news media to bottom-up messaging in which the platform influences the agenda power of legacy media, while maintaining a reciprocal relationship (Conway, Filer, Kenski, \& Tsetsi, 2017). Beyond the ability of one or another media outlet to set the agenda, the research focus is the convergence/divergence between the agenda of a platform like Twitter and that of the other media. Interest stems from the fact that, given the impossibility of analysing agendas that are privately shared by ordinary usersthrough platforms like Whatsapp or Telegram or in the networks of relations within Facebook, for exampleanalysis of the Twitter agenda assumes particular importance. Side by side with the traditional actors like politi- 
cians and journalists, Twitter also accommodates common users, activists/supporters of the various parties, organized groups, and so on. From this point of view, it offers an excellent vantage point from which to observe the convergence/divergence of the public agenda. Research carried out to date has revealed (albeit with different emphases and in different contexts) that the general tendency is towards convergence. In the context of the US presidential campaign, Stier, Bleier, Lietz, and Strohmaier (2018) reached the conclusion that the public agenda is still rather integrated, while Kang, Franklin Fowler, Franz, and Ridout (2018, p. 42) detect a "consistency in issue agendas between TV ads and tweets." In a different context from the election campaign, namely one of social mobilization during a debate about civil rights in California, Benkler, Roberts, Faris, Solow-Niederman, and Etling (2015, p. 594) identify and describe the existence of a "networked public sphere" which emerged as an alternative to the traditional media, yet remained interactive with them. Vargo and Guo (2017, p. 1047) place emphasis squarely on complementary interaction between agendas in concluding their research into the agenda of legacy media, news agencies, traditional media websites, online partisan media, and online nonpartisan media, when they state: "We found the network agendas of various media outlets to be highly interdependent, symbiotically networked and homogeneous. Media choices have increased dramatically during the past few years. Yet, the agenda of various media outlets were similar."

This traversal of the main lines of research into the existence or otherwise of a public agenda, following the advent of a high-choice media environment, presents a scenario which contains interesting pointers as to the direction to take in rethinking the very idea of a public agenda today. However fragmented, disrupted, and disconnected it appears, a public agenda is nonetheless still present in relation to the various media outlets.

Significant too is the presence of a cross-media information diet, bearing in mind that only a limited number of individuals admits to a monomedia diet (Dubois \& Blank, 2018). The data on individual multimedia diets call for a more comprehensive reading of the public agenda itself than those undertaken in the past. This ought to start by recognising that individuals - though able to select their own contents-have the chance to come into contact with different public agendas. This means that the denial tout court of a shared public agenda must be revised, bearing in mind that the individual continues to consume a composite media diet. It is moreover necessary to take into account the interrelations between the various agendas-which do not necessarily tend towards divergence.

It is a question, therefore, of abandoning a simplistic, reductive approach based on artificial distinctions, and adopting one which recognizes numerous and alternative ways of reading the public agenda. These include both individual and aggregative perspectives, which emerge through the relations between various platforms and which, in a nutshell, constitute the present-day expression of information convergence in contemporary society.

\section{The Constituent Dimensions of the Interrelated Public Agenda}

To recognize that it is still possible to talk about a public agenda in the current media ecosystem implies observing it as an 'interrelated public agenda,' the result of convergent and divergent mechanisms concerning the complex of legacy media, of online information environments (both those closely connected to the offline organs of information and native online news sites) and of social media, in which niche audiences contribute-thanks to their communicative activism - to give visibility to specific issues.

With this in mind, we propose three dimensions in order to describe public agenda interrelations: horizontality vs verticality, the personal vs the aggregative, and the dynamic vs the static. They represent three axes which, in our view, are useful in getting one's bearings among the various mechanisms that generate the agenda. At the same time, the axes: (a) highlight the joint presence of different and problematic elements, communication, and power pressures which ultimately create feedback loops, which make readings of the agenda itself increasingly complex; and (b) generate a continuum within which one has to move, adopting the perspective provided by a cross and multi-platform approach and taking into account communication flows and developments over time.

\subsection{Horizontality vs Verticality}

Starting with an analysis of the horizontality vs verticality dimension entails the immediate introduction of references to the intrinsic nature of the new media system, more and more characterised in terms of relations between environments and less and less able to "converge in the authoritative power to set the 'public agenda"' (Bennett \& Pfetsch, 2018, p. 249). This new order supersedes not only a public agenda that is built thanks to the exercise of 'authoritative power,' but also a power structure which is no longer reproducible in present-day societies. What in the past was the fruit of a balance of power between members of the political and media elites is today the fruit of direct or indirect interaction with other subjects. Thus, not only the range of voices to be heard in the public sphere has increased (Coleman, 2017), but also the number of those who can build that sphere.

To acknowledge the increase in the number of actors taking part in public agenda building obviously does not mean according all the actors equal roles: A privileged relation in power dealings between political elites and media elites is still clearly discernible, just as Reese (1991) noted years ago. At the same time, however, this 
can come under threat from the behaviour of individual subjects-such as online users - who can publicly express opinions and take positions with sufficient force to impact on the existing balance. This can happen through a sort of spontaneous, widespread mobilization or by organising collective action such as sharing and retweeting specific contents. The centrality conceded to social media by journalists and politicians alike amounts to a sort of precondition which holds them in constant tension, in search of expressions of support or possible opposition. Citizens and organised groups are therefore in a position-which does not always materialize but nonetheless exists - to directly influence the building of the public agenda.

Interaction between multiple communication platforms similarly revises existing power relations. Whether it is a question of social media, online news only, or sites of a different kind (the Breitbart site, for example), it is clear that power relations are being redefined. In this respect, the central role still accorded traditional media in deciding the public agenda (Djerf-Pierre \& Shehata, 2017) does not fully account for the complexity of the question. In fact, there are more and more cases in which it is the social media and online news sites that are really instrumental in developing a piece of news (Chadwick, 2013). The proliferation of information platforms and the possibility of sharing content through social media makes it impossible today to preserve a power balance, as in times gone by. The verticality of relations, between actors but also platforms and online news sites, belongs to the past, and the power which was once invested in certain media now serves to reinforce and legitimize what is broadcast by other subjects (Harder, Sevenans, \& van Aelst, 2017), in a perspective which is horizontal and interrelated.

In this sense, this dimension of the interrelated media agenda underlines the need to put issues relating to the intermediate agenda (as described in Section 2) at the centre of the analysis, in order to explore how new forms of salience of issues are produced, taking into account the temporal propagation between different media agendas and the creation of specific correspondences between agendas.

\subsection{Personal vs Aggregative}

The personal vs aggregative dimension is an analytical dimension which enables us to connect the numerous discussions and agendas produced both online and offline, ranging from those more oriented towards a personal dimension to those shared by a community of interests or by a community in its entirety. In this way, the synthesis at the root of agenda melding-i.e., "the social process by which we meld agendas from various sources, including other people, to create pictures of the world that fit out experiences and preferences" (McCombs et al., 2014, p. 794) - can be extended and also applied to the public agenda, as it is traditionally understood. This dimension is affected by the tension generated in the current media context between media spaces oriented towards personalization and the contexts, including technological ones which facilitate aggregation. We have mentioned how a high-choice media environment like the present one has acted-also from the viewpoint of the editorial strategies of both legacy media and online platformsso as to orientate the individual among the plethora of choices through the dynamics of personalization. This is particularly true for the digital exploitation of content, of both traditional and native media, which is regulated by algorithms which treat search behaviour and exploitation as data with which to nourish themselves. Previous choices become the premises for future choices, and this occurs in a context of connected social relations where even the choices of another user within the same media environment conditions the situation that the first user encounters.

At the same time, aggregation practices are typical of the digital environment-as in the example of hashtags which blend individual contents into a collective visibility stream. By means of its Trending Topics, Twitter, for example, highlights what the system considers up-andcoming topics, according to a kind of attention ranking which is reminiscent of a media agenda without actually being one. This logic of visibility with a view to being taken up by the mass media system is at the root, for example, of many hashtag activism ventures (Segerberg \& Bennett, 2011).

\subsection{Dynamic vs Static}

Finally, the dynamic vs static variable refers us to that fluid area which surrounds the relations between actors, between media platforms, and between the personal agenda and the public. It seems clear, in fact, that it is no longer possible to delimit rigidly the spaces of action and of relation, and that everything is placed in a relational context which changes extremely rapidly. This being so, it is important to orient research towards the relation between media spaces (and agendas) rather than concentrating on single-platform visions. To analyse the Twitter agenda-for example, specific themes dealt with in an aggregated manner by means of a hashtag-means taking account of thematic and discursive relations with other media or considering how other media are introduced to Twitter through sharing, and how these interrelations create an agenda which emerges from what happens on Twitter.

Furthermore, this axis indicates how the processual dimension becomes central in analysing the production of the interrelated media agenda, highlighting, for example, how, in a period marked by websites and online news constantly producing and disseminating information, the interval in which the media influence each other reciprocally is very variable, and while some issues are broadcast instantly others hover for longer on the outskirts of the media agenda and come to the fore later on (Conway et al., 2017). 


\section{The Interrelated Public Agenda and the "Unity of Difference" of Public Spheres}

The dimensions of the 'interrelated public agenda' need to be seen in relation to the challenges to our conceptualisation of the public sphere in a multiplicity of public spheres (Rossi \& Boccia Artieri, 2014). This multiplicity, however, needs to be seen in unity, beginning with the various spheres' decisive role from a political perspective, since "empirically, isolated 'public spheres' in time and space are highly unlikely phenomena due to the constantly circulating, flowing and leaking nature of communication" (Rasmussen, 2016, p. 80).

In this sense, public political discourse can be considered a uniform reality which, however, emerges in an increasingly differentiated manner in the context of a process of mediatization (Strömbäck \& Dimitrova, 2011) which features the joint presence of different media environments, online and offline, therefore involving differentiated publics as well as specific groups and subject matters. This position is not at odds with the conviction that we need to go beyond Habermas' model of the public sphere, nor does it clash with the idea of a more complex, dynamic, and multifaceted model which highlights the connections and overlappings of a multitude of coexisting public spheres.

Rather, rethinking the public agenda as interrelated requires the researcher to undertake observations that connect and differentiate at the same time: In other words, to observe a "unity of difference" (Luhmann, 1997) of the public sphere, it is a question of rethinking this "unity in difference" of the public sphere, not so much in relation to the idea that every media platformwhether legacy media or social media-generates its own public sphere as to the possibility to observe ' $a$ ' pub- lic agenda through the convergences and divergences of the various media agendas, taking convergence and divergence as two aspects of a single form, that of an 'interrelated public agenda.'

Rather than pursue an abstract, decontextualised idea of a cohesive, one-dimensional public agenda, it makes more sense to recognise the fact that today's public agenda is the product of convergences and divergences between media agendas. These can be analysed (see Figure 1) using the three dimensions we have just outlined in relation to emerging levels of the public sphere which tend towards ever more abstract forms of aggregations (Bruns \& Highfield, 2016).

These specific public spheres-technological (e.g., blogosphere, Twittersphere) or belonging to specific areas (like the political domain)-represent specific areas-even overlapping ones-within the more general Habermasian public sphere. Therefore, these public spheres do not move away from the idea that there is a current and constant public debate that concerns large audiences, audiences who are interested in a specific topic or deal with it within a specific media context (the blogger is a case in point).

We then find the production of "public sphericules" (Cunningham, 2001), which are formed by the aggregation of individuals around specific themes (e.g., human rights) and can also assume the form of counterpublics (in terms of agenda divergence). These "sphericules" carve out specific issues from more general domains and concern specific interest groups and narrower publics, not necessarily reflecting, nor empirically representing, the discourse of society. These are kinds of "vernacular voices" indicating the rise of a public that generates a discursive arena, an open exchange in a public sphere which has the ability to generate a sense of pub-

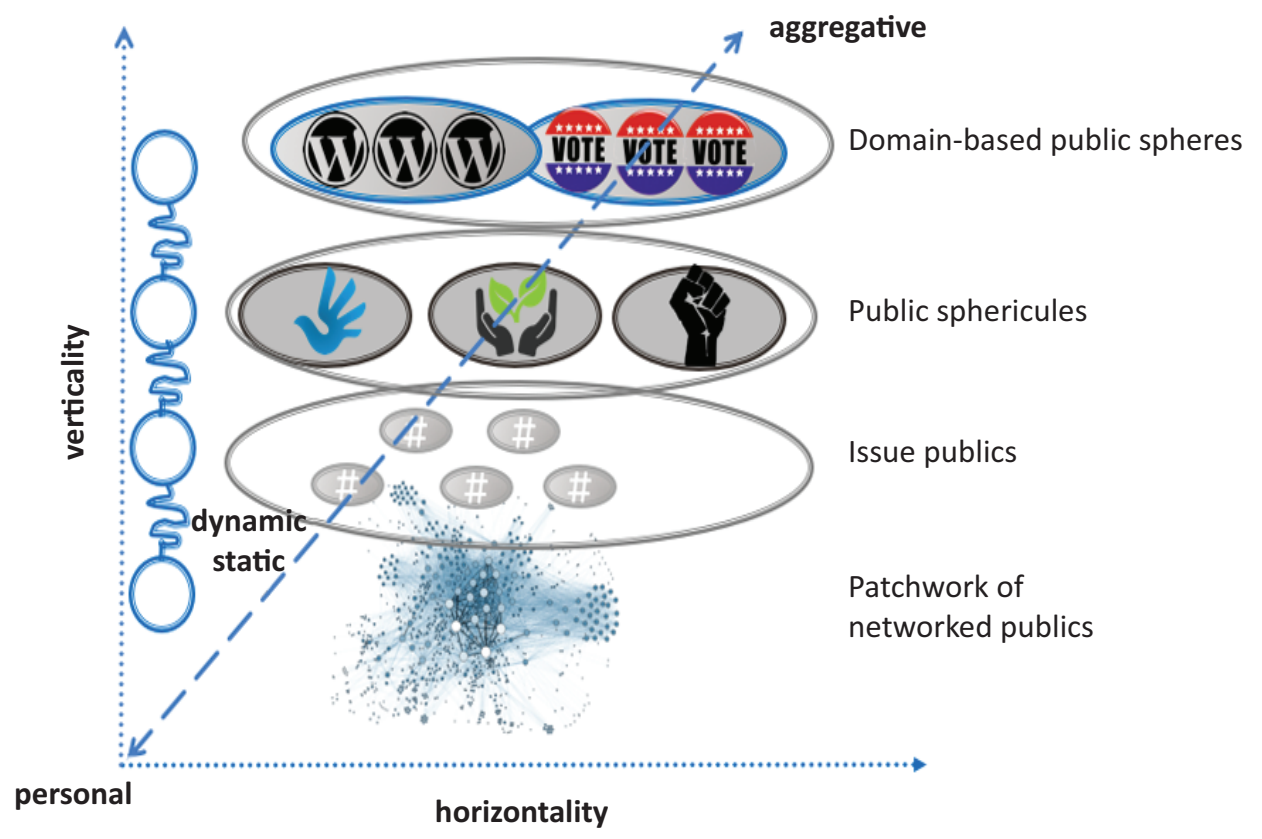

Figure 1. Dimensions of 'interrelated public agendas' and public spheres. Source: Authors composition. 
lic opinion (Hauser, 1999). These "voices" are outside of generative power, and this public discourse acts as fine tuning with respect to public opinion as an element of continuous tension in discursive production.

From a more general angle and from the viewpoint of globalization, "they provide a central site for public communication in globally dispersed communities, stage communal difference and discord productively, and work to articulate insider ethnospecific identities" (Cunningham, 2001, p. 135). If we consider "public sphericules" in the context which we have described, marked by the fragmentation of the public sphere and an information environment which complexifies the possibility of producing, distributing, and consuming information, we can observe how aggregation gives rise to a:

Communal process of gatewatching in which bloggers and citizen journalists identify and link to or directly cite relevant materials as they become available. Through such processes, content is reappropriated and reinserted into the public debate beyond the conventional spaces of the virtual, mass media stage. (Bruns, 2008, p. 68)

At a less abstract level, we find aggregations which emerge day by day around a specific issue and which nowadays find a way (especially on the web and via social network sites) of ensuring visibility-and researchability-for a debate which often peters out in a matter of days and involves a multitude of actors, institutional and otherwise, pressure groups, journalists, etc. In this sense, Habermas (2006) speaks of the emergence of "issue publics" as hubs around which the interest and conversation of a political public is focused. The unpredictability and variable success of the different issues "are influenced by everyday talk in the informal settings or episodic publics of civil society at least as much as they are by paying attention to print or electronic media" (Habermas, 2006, p. 416). In political communication, the practice of highlighting a specific issue by means of a hashtag is symptomatic of this desire to aggregate social media users and give them visibility as citizens holding a particular point of view. And this holds good whether it is played according to the verticality logice.g., by politicians imposing a specific hashtag in support of its position-or the horizontality logic, as in the case of hashtag activism when active citizens aim to aggregate other citizens. It needs stressing that individuals contribute to a variety of issues, to the extent that "the overlap of issue publics may even serve to counter trends of fragmentation" (Habermas, 2006, p. 422), suggesting that, in traversing the different issues, rather than the effect of separate echo chambers, one ends up by making them porous and interrelated by the discourses which converge and diverge in relation to themes which are becoming prominent.

A further level of aggregation are the networked publics (boyd, 2010), in which personal and public is- sues tend to converge and overlap, especially in structuring social networks which mix offline and online and find their most advanced expression in social network sites. In these media spaces, the multitude, the crowd, is transformed into a public, following the principle that every user, at one and the same time, is someone's public and has his or her own public. Agenda building here is a matter of alternating moments of production and consumption, of using private contents-narration, images, videos - to aggregate with public themes, and public contents-newspaper articles, photojournalism, news videos - to emphasise personal preferences and tastes (Boccia Artieri \& Gemini, 2019). For networked publics, the combination of posts, sharings, tweets, retweets, stories on Instagram, etc., and the thousands of comments, taggings, and reactions which contribute-through the algorithms - to give visibility to specific contents, merges with contents produced by the legacy media (and which often re-emerge in online spaces) and with face to face conversations, sometimes triggered by those online and sometimes interwoven with those online, since part of the public of every ego-network is made up of people with whom one associates, in various ways, in everyday life. This patchwork of networked publics therefore constitutes the less abstract level-even if supra-individualwhere public sphere themes and the various personal media agendas are part of the connecting tissue.

All this produces a need to focus on a complex context of 'interrelated public agendas' held in tension by horizontal and vertical forces, personal and aggregative orientations, and static and dynamic conditions, within a circular intermedia flow which moves between the more traditionally understood public sphere environment, represented by the general media, and the environment of thematic "public sphericules," and from here to the discussion of emerging "issue publics"-also in the wake of those built around online hashtags or communities of interest-before taking account of networked publics in which personal and collective thematic levels are seamlessly interrelated (Figure 1).

The connection flow which stems from this is made up of public themes, of editorial interests vis-à-vis typologies and niche publics, and of forms of direct engagement by the online publics themselves who, in searching for, commenting on, and sharing content and reacting publicly to it, build visible relations between the different agendas and produce retroactive effects at an editorial level.

\section{Conclusions}

This article has analysed the way in which contemporary political communication is conditioned by an information environment characterised, on the one hand, by increased choice, and on the other by the fragmentation and multiplication of the ways of consuming information. It has also dwelt on the way the consequences of this change have led to the current public sphere be- 
ing described in the literature as chaotic, fragmented, and disrupted. But this does not mean that today's 'dissonant' public sphere necessarily entails either the disappearance of the public agenda or a divergent, fragmentary, and multiple public agenda. More in general, as has been shown, studies on the intermedia agenda have highlighted how, in the current high choice media environment, there are strong connections as regards political communication between the legacy media agendas and the social media, and that forms of convergence (more frequent) and divergence (produced in any case by the interrelation of agendas) represent two aspects of the same coin.

In our opinion, the observation of an 'interrelated public agenda' requires us to take account of elements of convergence and divergence from a single viewpoint, adopting a complex analysis model which proceeds along axes that make a continuum visible, in which opposing forces are in a constant, problematic equilibrium. In this sense, we identified three dimensions which are helpful in describing public agenda interrelations.

First, the horizontality vs verticality dimension, containing the dynamics of power, generated in a context of political disintermediation through the altered nature of the media system-in the complex relation between legacy media and web 2.0, and between social, institutional actors, and others. Second, the personal vs aggregative dimension, which stresses the need to take account of convergences and divergences between personal orientation towards certain issues and the aggregative pressure in different media spaces in which people feel at home: from information consumption via media diets of varying complexity to active participation in the production of content or in public discourse, offline and online. And, finally, the dynamic vs static dimension, which points to the need to orient analysis towards the relationship between media spaces rather than focusing on specific spaces, thus helping, importantly, to make up for the current dearth of research in comparison with studies of single platforms. This relational perspective indicates that analysis of agendas and media spaces needs to be angled in terms of re-fero (reference to other agendas/media spaces), of re-ligo (in connection with other agendas/media spaces), and of the emerging context of the interrelated agenda in comparison with single, specific, aggregate agendas.

The three dimensions proposed: (a) make use of opposing poles as elements to account for the communication and power tensions in producing the agenda; and, at the same time, (b) point to the need to take into consideration a continuum between the poles in order to explain a state of flux.

These dimensions, typical of the 'interrelated public agenda,' can be read in relation to a public sphere model which takes into account fragmentation and disruptive elements, moving from a stratification which highlights the processes at work: This begins with more abstract levels, where we define public spheres in a segmentary man- ner; it then moves on to thematic "public sphericules" and "issue publics," down to the patchwork of networked publics in which personal and media agendas overlap and interweave.

To adopt this viewpoint therefore involves entertaining the possibility of dealing with the unity of agenda difference by means of a relational and flow-based approach, which makes it possible to bring out the dynamics of divergence and convergence and account for the evolution of the agenda over time. If the concept of agenda melding can be helpful in explaining, at an individual level, the effect/impression of harmony among the various agendas examined, at a systemic level this can be better accounted for by the concept suggested of an 'interrelated public agenda'-i.e., the outcome of the interaction of numerous reading levels. This includes the individual as well as the aggregate dimension, and takes shape thanks to the contribution of several platforms, as well as the numerous and varied logics which govern them. In this sense, the 'interrelated public agenda' is none other than the product of the contributions of numerous actors involved in various ways in the process of public agenda building, in continuous, unavoidable interaction determined by the specificities/peculiarities of the various communicative environments and by the interaction, direct or indirect, of the actors involved. The different public sphere agendas are thus treated as differentiations that operate along the same horizon, highlighting how the differences function within the same context.

\section{Conflict of Interests}

The authors declare no conflict of interests.

\section{References}

Benkler, Y., Roberts, H., Faris, R., Solow-Niederman, A., \& Etling, B. (2015). Social mobilization and the networked public sphere: Mapping the SOPA-PIPA debate. Political Communication, 32(4), 594-624.

Bennett, W. L., \& Iyengar, S. (2008). A new era of minimal effects? The changing foundations of political communication. Journal of Communication, 58(4), 707-731.

Bennett, W. L., \& Pfetsch, B. (2018). Rethinking political communication in a time of disrupted public spheres. Journal of Communication, 68(2), 243-253.

Blumler, J. G. (2016). The fourth age of political communication. Politiques de Communication, 1(6), 19-30.

Blumler, J. G. (2018). The crisis of public communication, 1995-2017. Javnost-The Public, 25(1/2), 83-92. https://doi.org/10.1080/13183222.2018.1418799

Boccia Artieri, G., \& Gemini, L. (2019). Mass media and the web in the light of Luhmann's media system. Current Sociology, 67(4), 563-578. https://doi.org/ $10.1177 / 0011392119837542$

boyd, d. (2010). Social network sites as networked 
publics: Affordances, dynamics, and implications. In Z. Papacharissi (Ed.), Networked self: Identity, community, and culture on social network sites (pp. 39-58). New York, NY: Routledge.

Bruns, A. (2008). Life beyond the public sphere: Towards a networked model for political deliberation. Information Polity, 13(1/2), 65-79.

Bruns, A., \& Highfield, T. (2016). Is Habermas on Twitter? Social media and the public sphere. In A. Bruns, G. Enli, E. Skogerbo, A. O. Larsson, \& C. Christensen (Eds.), The Routledge companion to social media and politics (pp. 56-73). New York, NY: Routledge.

Chadwick, A. (2013). The hybrid media system. Oxford: Oxford University Press.

Coleman, S. (2017). Can the internet strengthen democracy? Cambridge: Polity Press.

Conway, B. A., Kenski, K., \& Wang, D. (2015). The rise of Twitter in the political campaign: Searching for intermedia agenda-setting effects in the presidential primary. Journal of Computer-Mediated Communication, 20(4), 363-380.

Conway, B. A., Filer, C. R., Kenski, K., \& Tsetsi, E. (2017). Reassessing Twitter's agenda-building power: An analysis of intermedia agenda-setting effects during the 2016 presidential primary season. Social Science Computer Review, 36(4), 469-483. https://doi. org/10.1177/0894439317715430

Cunningham, S. (2001). Popular media as public 'sphericules' for diasporic communities. International Journal of Cultural Studies, 4(2), 131-147.

Dahl, R. (1998). On democracy. London and New Haven, CT: Yale University Press.

Dahlgren, P. (2005). The Internet, public spheres, and political communication: Dispersion and deliberation. Political Communication, 22(2), 147-162.

Djerf-Pierre, M., \& Shehata, A. (2017). Still an agenda setter: Traditional news media and public opinion during the transition from low to high choice media environment. Journal of Communication, 67(5), 733-757.

Dubois, E., \& Blank, G. (2018). The echo chamber is overstated: The moderating effect of political interest and diverse media. Information, Communication \& Society, 21(5), 729-745.

Habermas, J. (2006). Political communication in media society: Does democracy still enjoy an epistemic dimension? The impact of normative theory on empirical research. Communication Theory, 16(4), 411-426.

Harder, R. A., Sevenans, J., \& van Aelst, P. (2017). Intermedia agenda setting in the social media age: How traditional players dominate the news agenda in election times. The International Journal of Press/Politics, 22(3), 275-293.

Hauser, G. A. (1999). Vernacular voices: The rhetoric of publics and public spheres. Columbia, SC: University of South Carolina Press.

Kang, T., Franklin Fowler, E., Franz, M. M., \& Ridout, T. N. (2018). Issues consistency? Comparing television ad- vertising, tweets and e-mail in the 2014 Senate campaign. Political Communication, 35(1), 32-49.

Klinger, U., \& Svensson, J. (2015). The emergence of network media logic in political communication: A theoretical approach. New Media \& Society, 17(8), 1241-1257.

Kook Lee, J. (2007). The effect of the internet on homogeneity of the media agenda: A test of the fragmentation thesis. Journalism \& Mass Communication Quarterly, 84(4), 745-760.

Maier, S. (2010). All the news fit to post? Comparing news content on the web to newspapers, television and radio. Journalism \& Mass Communication Quarterly, 87(3/4), 548-762.

McCombs, M. E., \& Guo, L. (2014). Agenda-setting influence of the media in the public sphere. In R. S. Fortner \& P. M. Fackler (Eds.), The handbook of media and mass communication theory (pp. 249-268). West Sussex: John Wiley \& Sons.

McCombs, M. E., Shaw, D. L., \& Weaver, D. H. (2014). New directions in agenda-setting theory and research. Mass Communication and Society, 17(6), 781-802.

Pfetsch, B. (2018). Dissonant and disconnected public spheres as challenge for political communication research. Javnost: The Public, 25(1/2), 59-65.

Rasmussen, T. (2016). The internet soapbox: Perspectives on a changing public sphere. Oslo: Universitetsforlaget. Retrieved from https://www.duo.uio.no/ bitstream/handle/10852/52464/1/the-internetsoapbox-rasmussen.pdf

Reese, S. D. (1991). Setting the media's agenda: A power balance perspective. Annals of the International Communication Association, 14(1), 309-340.

Rossi, L., \& Boccia Artieri, G. (2014). Cyberprotest: Protest in the digital age. In K. Fahlenbrach, E. Sivertsen, \& R. Werenskjold (Eds.), Media and revolt: Strategies and performances from the 1960s to the present (pp. 336-350). Oxford and New York, NY: Berghahn.

Schudson, M. (1999). The good citizen: A history of American civic life. Cambridge, MA: Harvard University Press.

Segerberg, A., \& Bennett, W. L. (2011). Social media and the organization of collective action: Using Twitter to explore the ecologies of two climate change protests. The Communication Review, 14(3), 197-215.

Shaw, D., \& Weaver, D. (2014). Media agenda setting and audience agenda melding. In M. McCombs (Ed.), Setting the agenda: The mass media and public opinion (pp. 145-150). Cambridge: Polity Press.

Shehata, A., \& Strömbäck, J. (2018). Learning political news from social media: Network media logic and current affair news learning in a high-choice media environment. Communication Research. Advance online publication. https://doi.org/10.1177/ 0093650217749354

Stier, S., Bleier, A., Lietz, H., \& Strohmaier, M. (2018). Elec- 
tion campaigning on social media: Politicians, audiences, and the mediation of political communication on Facebook and Twitter. Political Communication, 35(1), 50-74.

Strömbäck, J., \& Dimitrova, D. V. (2011). Mediatization and media interventionism: A comparative analysis of Sweden and the United States. International Journal of Press/Politics, 16(1), 30-49.

van Aelst, P., Strömbäck, J., Aalberg, T., Esser, F., De Vreese, C., Matthes, J., . . Papathanassopoulos, S. (2017). Political communication in a high-choice me- dia environment: A challenge for democracy? Annals of the International Communication Association, 41(1), 3-27.

Vargo, C. J., \& Guo, L. (2017). Networks, big data, and intermedia agenda setting: An analysis of traditional partisan, and emerging online U.S. news. Journalism \& Mass Communication Quarterly, 94(4), 1031-1055.

Webster, J. G. (2014). The marketplace of attention. Cambridge, MA: The MIT Press.

\section{About the Authors}

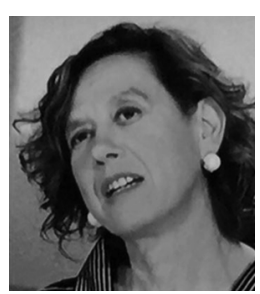

Sara Bentivegna (PhD) is Full Professor of Digital Media and Political Communication at Sapienza University of Rome. Her main research interests lay in the field of political communication, with specific focus on digital politics. Current research projects are about multiple agendas in a time of disrupted public spheres. She has published many articles in national and international journals such as European Journal of Communication, Journalism, Journalism Studies, and Contemporary Italian Politics.

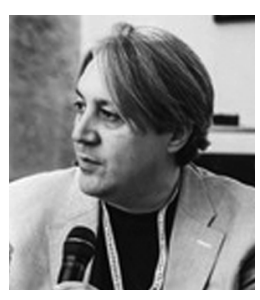

Giovanni Boccia Artieri (PhD) is Full Professor in Sociology of Communication and Digital Media and Dean at the Department of Communication Sciences, Humanities and International Studies, University of Urbino Carlo Bo. He is Coordinator of the PhD Program on Humanities. His main research interests revolve around media theory, with a focus on social media and participatory culture. He has published many articles in national and international journals such as Information, Communication \& Society, Current Sociology, International Journal of Communication, and Participations: Journal of Audience \& Reception Studies. 